\title{
The East Atlantic and Mediterranean bluefin tuna stock management: uncertainties and alternatives*
}

\author{
JEAN-MARC FROMENTIN
}

IFREMER, Centre de Recherche Halieutique Méditerranéen et Tropical, BP 171, 34203 Sète Cedex, France.

E-mail: Jean.Marc.Fromentin@ifremer.fr

\begin{abstract}
SUMMARY: Although the Atlantic bluefin tuna has been studied for more than a century, the assessment of the East stock is characterised by a large amount of uncertainty. In 2000, this situation became so critical that quantitative stock assessment has been postponed. The first part of the present study aims to list the main difficulties that have led to the current situation and tries to discern between subjective and objective uncertainty. The former, which is due to an incomplete knowledge of the system and which has increased in the past few years, is mainly due to a decreasing quality of the catch and effort data, that has followed the establishment of a TAC. The latter source of uncertainty, which results from the underlying variability in stochastic processes, mainly relates, for this species, to spatial and temporal changes in stock size, growth and migration. The second part of this study presents the results of simulation modelling, which could be, in the meantime, an useful tool for short-term management of the East Atlantic and Mediterranean BFT stock.
\end{abstract}

Key words: variability, spatial and temporal fluctuation, catch, fishing effort, stock assessment, growth, simulation modelling, GLM.

\section{INTRODUCTION}

In the last few years the Atlantic bluefin tuna (BFT) fisheries has become a highly profitable activity: one single fish can be sold for more than 50,000 US $\$$ on the Tokyo market and this situation has induced tensions between administrations, professionals and scientists. The BFT fishery is, however, traditional in the Mediterranean Sea; the first evidences of tuna fishing are estimated at around 7000 years BC (Desse and Desse-Berset, 1994; Doumenge, 1998). In relation to this long fishing history, bluefin tuna has been constantly studied. The ancient Greek and Latin philosophers Aristotle

\footnotetext{
*Received December 6, 2000. Accepted December 21, 2001.
}

(fourth century BC) and Pliny (first century A.C.), already mentioned the BFT migration patterns in their natural history works and scientists have been studying the BFT biology and its fisheries since the late $19^{\text {th }}$ century (e.g. Bragança, 1899; Sella, 1929; Rodriguez-Roda, 1964).

Like all the Atlantic tunas, BFT is managed by the International Commission for the Conservation of the Atlantic Tuna (ICCAT). A specific working group of scientists perform used to a complete stock assessment every 2 years since 1970. The assessment procedure is based on an aged structured population model (ADAPT type), in which CPUE series are used for tuning. In 2000, the quantitative stock assessment procedure was, for the first time postponed, because of increasing uncertainties concern- 
ing the catch and effort data, combined with a lack of information of key biological and ecological processes (ICCAT, 2001). The present study intends to list the main sources of uncertainties which make the traditional stock assessment inoperative, and to present results obtained with simulation modelling.

\section{MAIN SOURCES OF UNCERTAINTIES IN THE BFT ASSESSMENT PROCEDURE}

\section{Uncertainties related to the catch data}

Under- and mis-reporting is the main source of uncertainty related to catch data (Table 1). Though most of the countries fishing BFT are now ICCAT members (i.e. they have to report yearly catches), ICCAT official statistics are unfortunately highly erroneous. This was explicitly demonstrated in 1998, when several countries asked for a revision of the official ICCAT statistics for the 1991-1997 period. This request was actually motivated by the implementation of a TAC in 1996; the quota of each country being proportional to its historical catches. Not so surprisingly, this revision led to a 20 to $25 \%$ increase in the total catches and secondarily to a discrepancy in the catch-at-age matrix (note furthermore that the situation is worst with the non-contracting parties who are not obliged to declare their catches). The second problem is related to the fishing of age 0 and 1 . This activity is known to be important in several Mediterranean countries, but it is poorly reported as it is officially forbidden, size limit being fixed at $6.4 \mathrm{~kg}$ (with a tolerance of $15 \%$ for fish between 3.2 and $6.4 \mathrm{~kg}$ ). This widespread under-reporting, which results from both industrial and small-scale fisheries, is impossible to evaluate accurately and strongly biases the assessment and management procedures. Flags of convenience are another source of errors, which has been known for years for most of the tuna fisheries. This leads to an additional source of under-reporting, which is difficult to estimate.

TABLE 1. - Main sources of uncertainties related to the catch data

\begin{tabular}{cc}
\hline Main uncertainties & Impact on stock assessment \\
\hline Under- and mis-reporting & Crucial importance \\
Illegal catches of 0-group BFT & Very important and significant \\
Flags of convenience & Important and significant \\
\hline
\end{tabular}

TABLE 2. - Main sources of uncertainties related to the fishing effort

\begin{tabular}{cc}
\hline Main uncertainties & $\begin{array}{c}\text { Impact on stock assessment } \\
\text { and CPUE }\end{array}$ \\
\hline Changes in gear-technology and tactics & Crucial importance \\
New selectivity pattern and fishing area & Very important and significant \\
Vessels cooperation and competition & Very important and significant \\
Fishing in restricted areas & Important and significant \\
\hline
\end{tabular}

\section{Uncertainties related to fishing effort}

Changes in gear-technology and tactics mainly affect the purse seiner fleet, which is the largest one (about $60 \%$ of the total landings) and secondarily the baitboat fleet (Table 2). In comparison to 1970, a standard purse seiner was in 1998 twice as long and four times more powerful. Though such a change can easily be modelled, it is more difficult to model objectively the recent increasing use of powerful positioning and prospecting equipment, such as bird radar, sounder, sonar and plane as well as new storage equipment, such as carrier vessels with deep freezing storage and pool systems (Liorzou, 1999). Because big tuna have a considerably higher value on the Japanese market, the purse seiner fleet, that used to target small fish until the 1980s, now targets both small and big fish. Subsequently, purse seiners strongly expanded their fishing area in the Mediterranean and, during the same period, the long liners did the same in the central North Atlantic. Such changes in both selectivity and fishing area are known to bias the effort estimate and, thus, the CPUE indices. A third source of uncertainty relates to the vessels' cooperation and competition. Purse seiners tend to work in teams of about 5 boats. As soon as a boat catches a school, it shares its catch with its partners but also with boats of other teams if the latter arrives at the fishing location before the former has finished surrounding the school with its seine. The teams change from year to year and there is strong competition between them. These changes, which affect fishing effort positively and negatively, are highly difficult to quantify without a detailed information provided by observers. Fishing in restricted areas is also of importance for BFT, because this can lead to local overfishing (see e.g. Fonteneau and Fromentin, 2000). For BFT, this problem mainly concerns the baitboat fleet, which historically targets young BFT in the southern Bay of Biscay. 
TABLE 3. - Main sources of uncertainties related to modelling

\begin{tabular}{cc}
\hline Main uncertainties & Impact on stock assessment \\
\hline $\begin{array}{c}\text { The ageing procedure } \\
\text { structured model } \\
\text { Technical specifications in the age- }\end{array}$ & Crucial importance \\
$\begin{array}{c}\text { Inadequacy of the projection model } \\
\text { Impont and significant }\end{array}$ & Very important and significant \\
\hline
\end{tabular}

\section{Uncertainties related to modelling}

The stock assessment process includes several numerical steps: (i) an ageing procedure to estimate the catch-at-age matrix from the length and weight data, (ii) CPUE indices for the tuning of the VPA, (iii) the aged structured model, here ADAPT-VPA version (Geromont and Butterworth, 1997; Porch, 1997), to evaluate fishing mortality parameters and stock size estimates and (iv) a projection modelling for short-term and medium-term predictions. The crucial problem probably relates to the ageing procedure, which is estimated through a Von Bertalanffy growth model and a slicing method (Table 3). A recent analysis of the catch-at-age data revealed important problems that could be due to: (i) the fact that the fisheries switched from younger to older age groups (see above) and (ii) the slicing method (Anonymous, 1998). The modes for the youngest ages are indeed correctly distinguished within the length or weights distributions, but there is considerable overlap for older ages, especially for fish older than 5 years. This difficulty is further reinforced by spatial and temporal variations in growth (see below). Simulation studies have revealed that a mis-

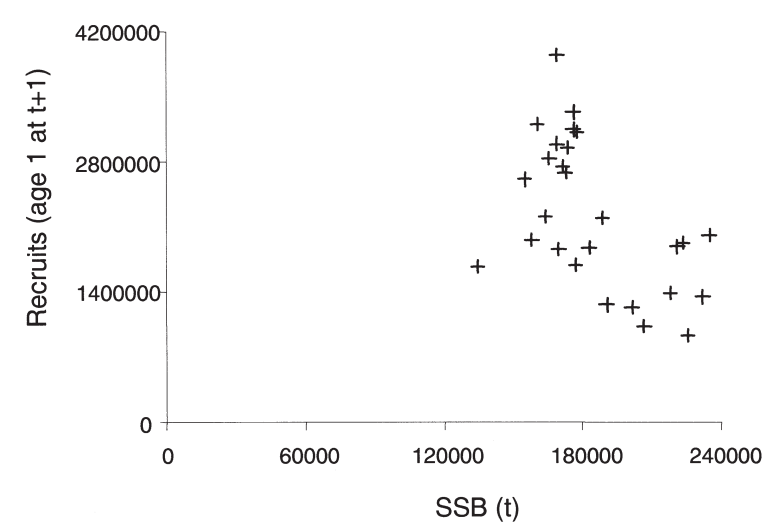

FIG. 1. - Scatterplot between the spawning stock biomass (tonnes) and the number of recruits (age 1); both variables being estimated by the 'BFT-ICCAT working group' through an ADAPT-VPA model. assignment of about $20 \%$ between the different age classes (a percentage considered moderate by biologists), induced a severe under-estimation of the fishing mortality (Anonymous, 1998). Uncertainties related to the technical specifications mainly relate to the natural mortality (see below). Projections tend to be based on the Beverton and Holt model (Beverton and Holt, 1957). However, the BFT SSB/recruitment relationship appears rather fuzzy (a classical difficulty in fisheries science, Fig. 1), which could be due to stochasticity in the recruitment. BFT indeed feeds over the entire North Atlantic but only reproduces in a small spatial and temporal window (around the Balearic islands and Sicily in June). BFT recruitment is thus likely to be more variable than that of tropical tuna (Fromentin and Fonteneau, 2001).

\section{Uncertainties related to a lack of biological and ecological information}

This type of uncertainty is often neglected although it is a major one. As for other stocks, our lack of knowledge of the natural mortality (M) of the Atlantic BFT is of crucial importance (Table 4). For BFT, the closest estimates of $\mathrm{M}$ are probably those obtained from tagging experiments on a related species: the Southern bluefin tuna. These estimates showed that $\mathrm{M}$ was age-specific and about 5 times higher for juveniles than adults (ICCAT, 1997), which is in agreement with the ecological and biological theory (Wootton, 1990). There are thus few arguments for continuing to use a constant $\mathrm{M}$ for all the ages, but it appears necessary to carry out an intensive tagging experiment in order to estimate $\mathrm{M}$ for the Atlantic BFT. Stock delimitation is an old and unsolved problem. Bluefin tuna is a highly migratory species and is widely distributed throughout the entire North Atlantic and adjacent seas. Based on distinct spawning areas and different age-at-maturity, ICCAT uses two stock-assessment units: the West Atlantic and the East Atlantic and

TABLE 4. - Main sources of uncertainties related to a lack of biological and ecological information

\begin{tabular}{cc}
\hline Main uncertainties & Impact on stock assessment \\
\hline Natural mortality & Crucial importance \\
Stock assessment units & Very important and significant \\
Long-term fluctuations & Very important and significant \\
Variation in growth & Very important and significant \\
\hline
\end{tabular}




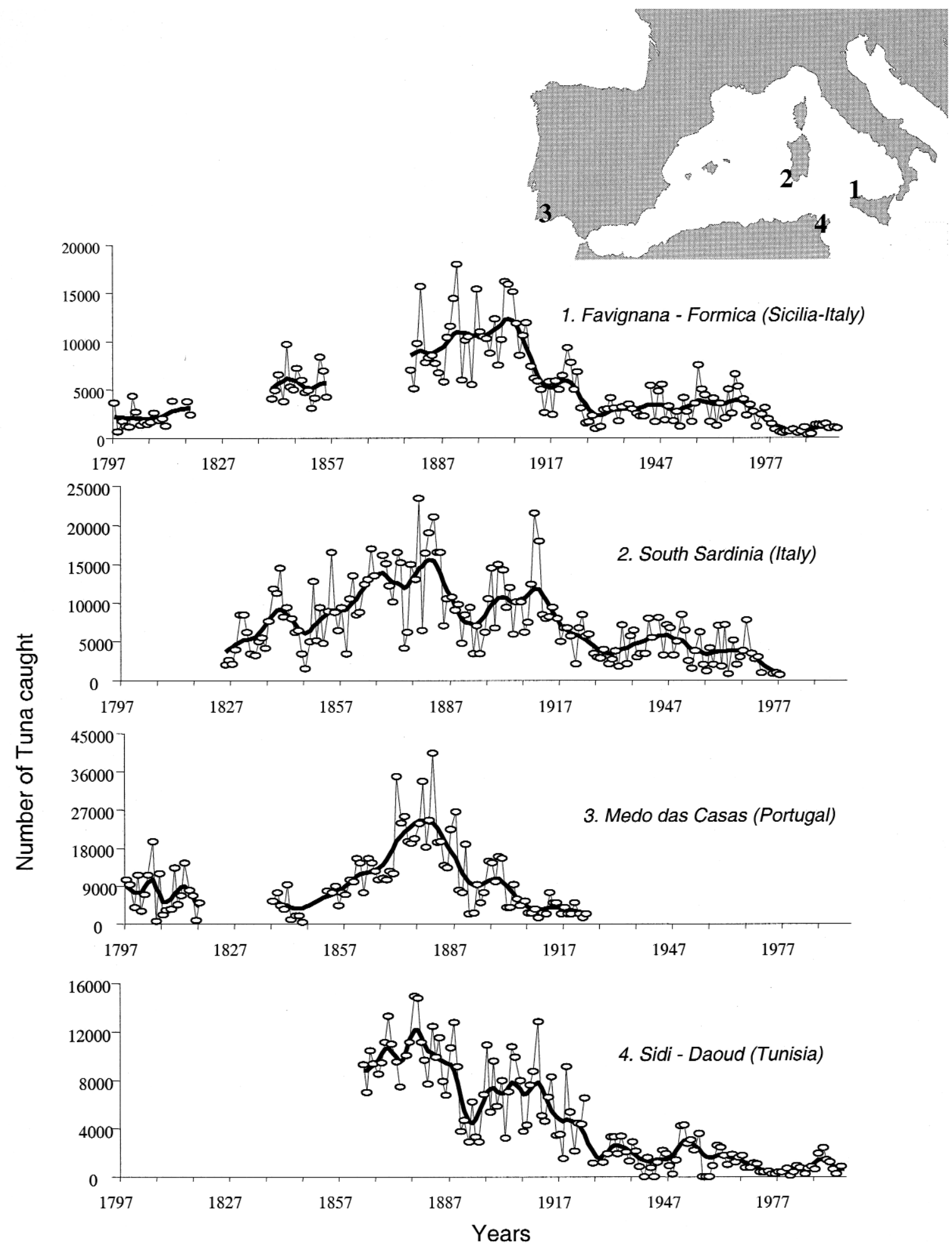

FIG. 2. - Catches (number) of bluefin tuna of 4 important Mediterranean and East Atlantic trap fisheries over the two last centuries. Open circles: raw data (connected by a thin line); thick line: kernel smoothing.

Mediterranean, being divided by the $45^{\circ} \mathrm{W}$ parallel. Although migrations have been shown to occur between the two management units (Block et al., 2001; Lutcavage et al., 1999; Tiews, 1963), much more tagging data are still needed to obtain reliable estimates of the transatlantic migration rates (ICCAT, 2002; Porch and Turner, 1999). As 95\% of the catches are made in the East Atlantic, the issue 


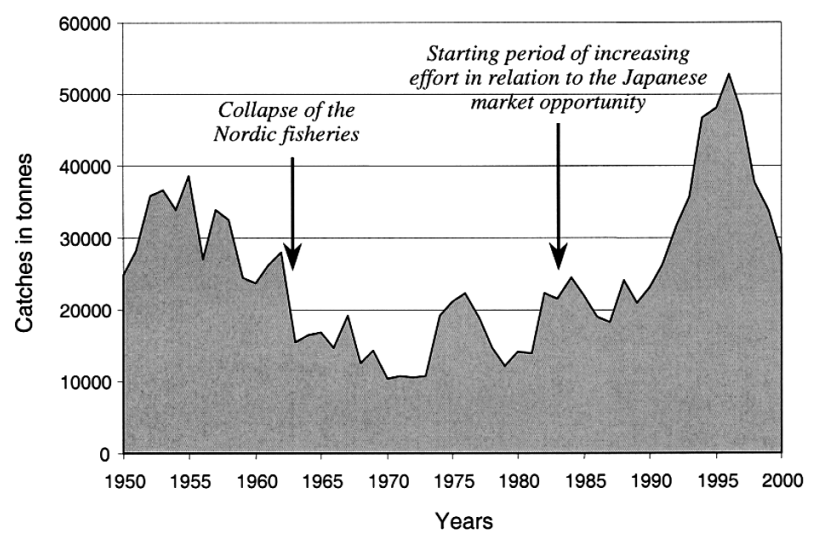

FIG. 3. - Total landings (in tonnes) of the East-Atlantic and Mediterranean bluefin tuna from 1950 to 2000 (ICCAT source).

related to the stock delimitation is of major importance for the West Atlantic BFT assessment. A third important problem relates to the long-term fluctuations in the catches. Variation in the historical trap catches (Fig. 2) have been related to changes in stock size (Ravier and Fromentin, 2001), whereas the sudden disappearance of the Nordic fisheries in the early 1960s (Fig. 3) has been attributed to changes in migration patterns (Pusineri et al., 2002; Tiews, 1978). Only the sharp increase since the 1980s has been directly attributed to fishing (Fig. 3). Though long-term fluctuations that are environmentally driven have been shown for many fish stocks (see e.g. Cushing, 1982), projection models and reference points assume that fish populations are stationary. This assumption seems to be invalid for the Atlantic BFT.

A first examination of the ICCAT BFT tagging database suggests that growth is also highly variable between areas and between years or decades. For instance, two fishes of $81 \mathrm{~cm}$ and $55 \mathrm{~cm}$ were marked in 1960 and 1976 respectively, and both were recaptured 14 years later at $256 \mathrm{~cm}$ and $400 \mathrm{~kg}$ and $292 \mathrm{~cm}$ and $353 \mathrm{~kg}$ respectively. Such variations, which have been already shown for various fish populations (e.g. Astthorsson and Gislason, 1998; Nilssen et al., 1994; Sogard, 1992; Wootton, 1990), become critical for long-lived species such as BFT. To investigate this potential source of variability, we here followed a recommendation of the fifth SAP meeting to investigate the variations in the weight-at-age $\left(\mathrm{W}_{\mathrm{a}, \mathrm{t}}\right)$.

\section{Modelling weight-at-age}

Because of the various problems in the ICCAT database and aggregation among different areas, we restricted our analysis to the records of the French landings by purse seiners between 1982 and 1998. French purse seiners typically target juveniles $<30-35 \mathrm{~kg}$ (ages 1 to 3 ) in the Gulf of Lions and the Ligurian Sea in spring, late summer and fall. Until 1998, the French administration did not routinely collect logbooks from the Mediterranean vessels, so we used the sales records of the local seafood traders, which covered between $70 \%$ and $100 \%$ of the landings of the BFT juveniles caught by the French purse seiners (for more details, see Labelle et al., 1997). All the records were checked and those including suspicious or incomplete information were removed. 13,201 records were finally kept and used to compute the monthly mean weights (MW) for each age and each year between 1982 and 1998 (i.e. 612 MW). A graphical examination of the MW did not reveal any doubtful patterns (Fig. 4, MW spread from $\sim 3 \mathrm{~kg}$ at the beginning of a given year to $\sim 8 \mathrm{~kg}$ at the end of it for age 1 , from $\sim 8 \mathrm{~kg}$ to $\sim 16 \mathrm{~kg}$ for age 2 and from $\sim 16 \mathrm{~kg}$
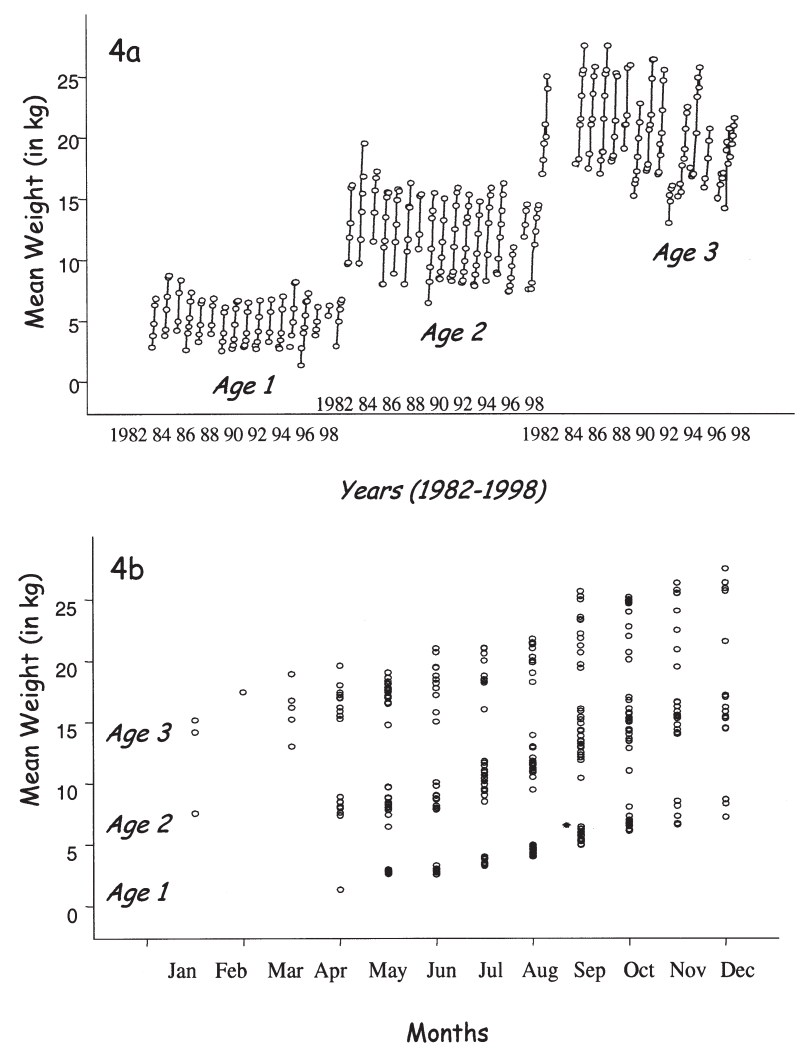

FIG. 4. - Monthly mean weights (MW) of juvenile bluefin tuna of age 1,2 and 3, obtained from the sale records of the French seafood traders between 1982 and 1998; a: Scatterplot of the MW of age 1, 2 and 3 (open circles) against the years (the values corresponding to the different months of a same year and age are connected by a line; b: Scatterplot of the MW of age 1,2 and 3 (open circles) against the months (different values take place in a same month because of different years and ages). 
to $\sim 25 \mathrm{~kg}$ for age 3 ). Note, however, the lack of data in years 1983 and 1984 for age 3 (Fig. 4a) and the missing values in January, February and March for all the ages (Fig. 4b). For this reason, we excluded the three winter months from the analysis (the final data set containing $459 \mathrm{MW}$ ), whereas the missing years for age 3 (i.e. 1982 and 1983) were treated as missing values and the corresponding lines omitted (S-Plus, 1999).

We investigated the weight-at-age data using the framework of the Generalised Linear Models (GLM, McCullagh and Nelder, 1989). Following Shepherd and Nicholson (1991), we assumed that weight-atage could be modelled as:

$$
W_{a, t} \sim f(\text { Age, Month, Year })
$$

Age could be assumed as the 'mean effect' and Month as the 'seasonal effect' (the BFT growth being faster in summer and fall, see Figure $4 \mathrm{~b}$ and also Labelle et al., 1997; Mather et al., 1995). Year was the variable of main interest and represented 'the year-to-year effect'. In contrast to Shepherd and Nicholson (1991), we did not introduce a 'year class effect' (i.e. density-dependence) because the year class estimates from the VPA were not trustworthy. Note however that density-dependent processes have not been demonstrated for tuna and remain less probable for these highly migratory and pelagic fish than for demersal ones.

As we regressed the MW against three categorical variables, we had to define the contrast matrix to obtain the $k$ coefficients of each factor ( $k$ corresponding to the numbers of levels of each factor). We used the treatment contrast which was recommended for unbalanced layouts, including the GLM (Venables and Ripley, 1999). These unconstrained coefficients obtained directly from the fit were furthermore easy to interpret, each coefficient representing a comparison of its level with the first level. To incorporate the variability due to the sampling error or to stochastic processes not being integrated in the 'Month or Year effect', we defined a function for the conditional variance, which was the law for the variability around the deterministic model (McCullagh and Nelder, 1989). The Normal quantiles of the MW for the different ages clearly indicated that the MW were not normally, nor log-normally, distributed. Therefore, we selected a GLM with a Gamma error and a log-link. All the calculations were made using SPlus 2000 (S-Plus, 1999).
TABLE 5. - Results of the ANOVA of the fitted Generalized Linear Model (with a Gamma error and a log-link), with the different terms added sequentially (first to last).

\begin{tabular}{lcc}
\hline Models & Degree of freedom & Residual Deviance \\
\hline NULL & 304 & 103.436 \\
Age & 302 & 19.367 \\
Month & 294 & 5.211 \\
Year & 278 & 3.877 \\
Age * Month & 263 & 1.308 \\
\hline
\end{tabular}

\section{Results of the weight-at-age analysis}

The MW appeared clearly distinct between the ages (Figs. $4 \mathrm{a}$ and $4 \mathrm{~b}$ ), with a mean at around $5 \mathrm{~kg}$, $12 \mathrm{~kg}$ and $20.4 \mathrm{~kg}$ for ages 1 to 3 respectively. The seasonal pattern was also clear for all the ages, with a quicker growth in the second half of the year (Fig. $4 \mathrm{~b})$. The seasonal and yearly variations in MW appeared lower for age 1 than for ages 2 and 3. The latter further exhibited a decreasing trend over the 1982-1998 period (Fig. 4a). This cursory examination would indicate a significant 'Age and Month effect' and possibly a 'Year effect', at least for ages 2 and 3.

Without an interaction term between 'Age' and 'Month', the residuals clearly exhibited underlying structure, so we finally fitted the following model: $\mathrm{MW}=f($ Age + Month + Year + Age*Month); this being due to the poor sample of age 1 during early spring and late fall. The GLM with a Gamma error term and a log-link was able to explain most of the variance of the MW. The residuals deviance of this model fell from 103.4 (304 degrees of freedom) to 1.3 (263 degrees of freedom, Table 5). The residuals as well as the squared root of the absolute values of the residuals did not exhibit any special structure (Figs. 5a and $5 b)$. The goodness of fit was very satisfactory, as was shown by the plot of the fitted values versus the MW (Fig. 5c) and the Pearson residuals (i.e. residuals scaled by their variance) were normally distributed, as expected (Fig. 5d).

The results of the ANOVA of the GLM, which gave the analysis of deviance table (Table 5), showed that the 'Age effect' was, as expected, the most important factor, and then came the 'Month effect'. The Age coefficients indicated that age 2 contributed more than age 1 , and age 3 more than ages 1 and 2 , reflecting that the variance in weight was proportional to the age (a feature known empirically, Table 6, but see also Fig. 4). The Month coefficients clearly 

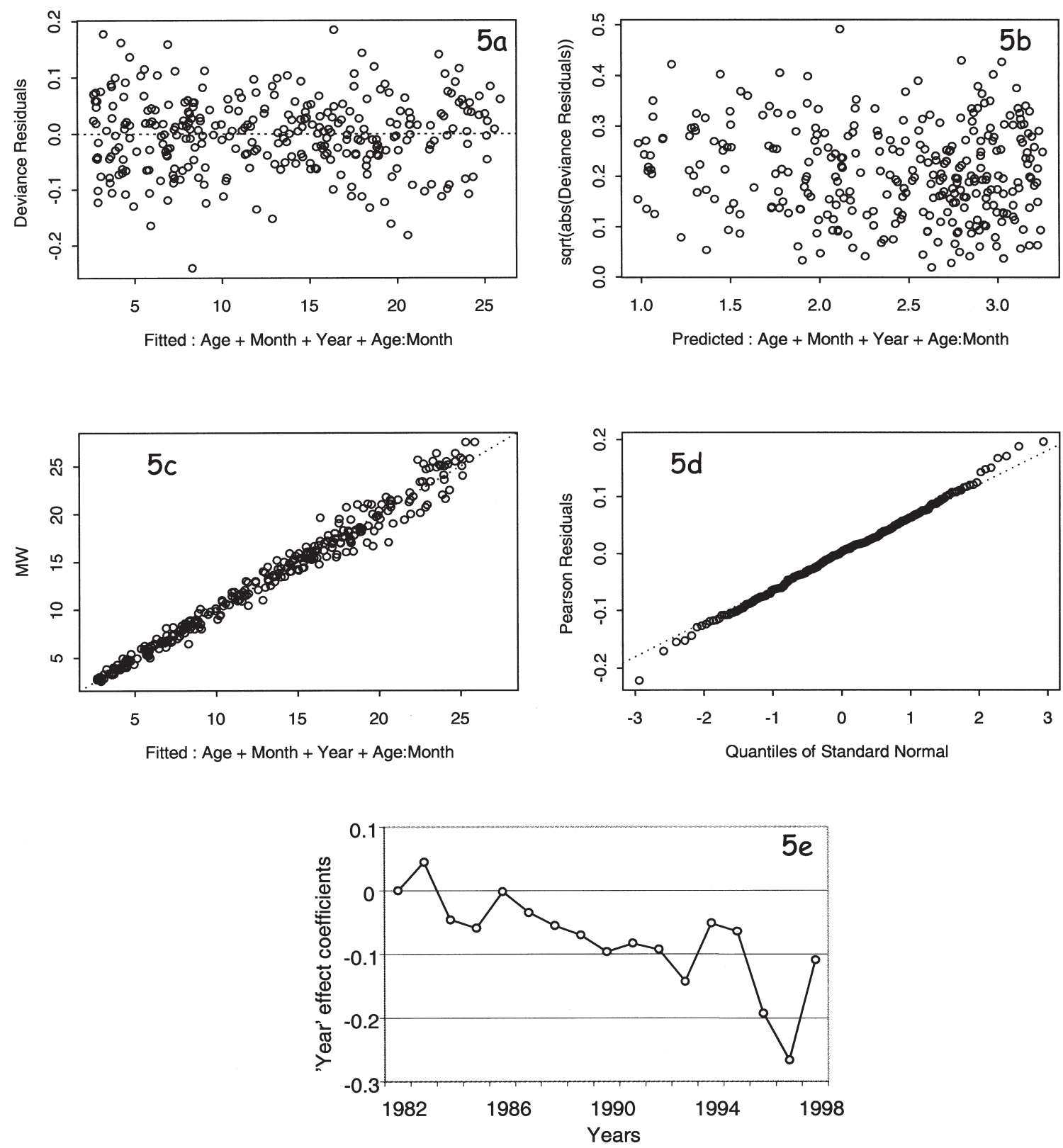

FIG. 5. - Results and diagnostic of the GLM with a Gamma error and a log-link; $\mathbf{a}$ and $\mathbf{b}$ : plots of the residuals and of the squared root of the absolute values of the residuals; c: plot of the fitted values versus the MW; d: Normal quantiles of the Pearson residuals (i.e. residuals scaled by their variance); e: plot of the 'Year effect' coefficients.

illustrated the seasonal growth of juveniles BFT, early fall appearing as the typical growing season for young BFT (Table 6). Though the two other terms (i.e. the 'Year effect' and the interaction 'Age*Month') accounted for a smaller part of the total deviance, the 'stepAIC' function (pp. 186-188 in Venables and Ripley, 1999) indicated that these variables were also significant. 1982, 1983 and 1986 were characterised by relatively high MW, whereas relatively low MW occurred in 1993, 1996 and 1997 (Table 6). Furthermore, the MW decreased significantly over the whole period (Fig. 5e).

\section{Discussion on the weight-at-age analysis}

The above analysis showed that the variations in weight-at-age of the BFT juveniles in the Gulf of Lions and the Ligurian Sea significantly displayed significant year-to-year variation. To validate the present results, this analysis should be re-computed on a more extensive data set, which would include the main Mediterranean and East Atlantic fisheries of BFT juveniles (by adding for instance an 'Area effect'). However, the present analysis leads to two interesting results. Firstly, the clear increase in the 
TABLE 6. - Coefficients of the intercept and of the $k$ levels of the 'Age', 'Month' and 'Year' factors, considering the treatment constrasts for the contrast matrix (see Venables and Ripley, 1999).

\begin{tabular}{|c|c|c|c|c|c|}
\hline Intercept & Age & Month & & $\mathrm{Ye}$ & \\
\hline 1.402526 & $\begin{array}{ll}\text { Age 1 } & 0 \\
\text { Age 2 } & 0.467 \\
\text { Age 3 } & 1.177\end{array}$ & $\begin{array}{l}\text { April } \\
\text { May } \\
\text { June } \\
\text { July } \\
\text { August } \\
\text { September } \\
\text { October } \\
\text { November } \\
\text { December }\end{array}$ & $\begin{array}{l}0 \\
-0.603 \\
-0.606 \\
-0.363 \\
-0.175 \\
0.097 \\
0.258 \\
0.315 \\
0.385\end{array}$ & $\begin{array}{l}1982 \\
1983 \\
1984 \\
1985 \\
1986 \\
1987 \\
1988 \\
1989 \\
1990 \\
1991 \\
1992 \\
1993 \\
1994 \\
1995 \\
1996 \\
1997 \\
1998\end{array}$ & $\begin{array}{l}0 \\
0.044 \\
-0.047 \\
-0.059 \\
-0.001 \\
-0.036 \\
-0.055 \\
-0.071 \\
-0.096 \\
-0.084 \\
-0.093 \\
-0.142 \\
-0.051 \\
-0.065 \\
-0.193 \\
-0.266 \\
-0.109\end{array}$ \\
\hline
\end{tabular}

variability in weight from age 1 to 3 suggests that the underlying processes, variation in growth and/or in condition, are important during the juvenile period. Secondly, the apparent decline in the mean weights over the 1982-1998 years for age 2 and 3 is intriguing and could be a sign of growth overfishing. This point deserves further investigation.

\section{ONE ALTERNATIVE METHOD: SIMULATION MODELLING}

Temporal variability in stock size, growth, recruitment or migration patterns actually refer to what is commonly named 'objective uncertainties', i.e. uncertainties resulting from the underlying variability in stochastic processes. These uncertainties could be opposed to the 'subjective uncertainties', which mainly relate to an incomplete knowledge of the system or a mis-operating of the management, here mainly uncertainties related to the catch data and fishing effort. Improving standard stock assessment procedure, which is in the present situation unfeasible, would firstly involve reducing these subjective uncertainties. Even so, scientists still have to give advice on this stock, which is suspected to be overfished for several years (ICCAT, 1999). One way is to use alternative methods being developed for short-term management purposes. Among several possibilities, we here present results based on simulation modelling.

Simulation modelling can be a powerful tool, especially for testing various hypotheses, if the modelling assumptions are clearly stated. We here pre- sent results of a simple simulation model that has been designed to test the effects of variations in recruitment and the impact of different selectivity patterns on the spawning stock biomass and the yields. The first point was motivated by the fact that the East and Mediterranean BFT populations reproduce only once a year in a small spatial and temporal window, so variations in recruitment are likely. The second point follows a change in the strategy of the purse seiner fisheries which now strongly target the adults, so both juveniles and adults are now significantly exploited.

\section{Presentation of the simulation model}

The simulation model that we used here is based on the fundamental equation of fish population dynamics:

$$
N_{a, t}=N_{a-1, t-1} e^{-Z t}
$$

where, $N_{a, t}$ is the number of fish of age (a) at time $(\mathrm{t})$, and $\mathrm{Z}$ the total mortality from age (a-1) to age (a). $\mathrm{Z}=\mathrm{M}+\mathrm{F}$, with $\mathrm{M}$ being the natural mortality and $\mathrm{F}$ the fishing mortality. The simulated BFT populations are based on the main biological characteristics: yearly spawning, life span of 20 years, maturity at 4.5 years (Mather et al., 1995). As densitydependent processes have not been clearly established for tunas, we did not introduce densitydependent mortality within juvenile stages (Fromentin et al., 2001; Myers and Cadigan, 1993; Porch et al., 2001). The natural mortality of East Atlantic BFT is based on estimates of the Southern bluefin tuna and is about 5 times higher for juveniles (0.49) than adults (0.1, see ICCAT, 1997). Mean weights spread from $4 \mathrm{~kg}$ at age 1 to $400 \mathrm{~kg}$ at age 20. We assumed a Beverton and Holt stock/recruitment relationship (Beverton and Holt, 1957) because this model is currently used within the 'ICCAT BFT working group'. As seen previously, this S/R relationship did not fit the BFT VPA estimates but it is used here for theoretical purposes (simulations conducted with a Ricker stock/recruitment model lead to equivalent results). Because of the effects of year-to-year fluctuations in environmental conditions and/or predation on the recruitment (e.g. Cushing, 1995; Hjort, 1914; May, 1974; Wooster and Bailey, 1989), we included a random noise component, $\varepsilon$, which is Gamma distributed (Engen and Lande, 1996) with mean and standard deviation equal to 1 (i.e. moderate variance). 


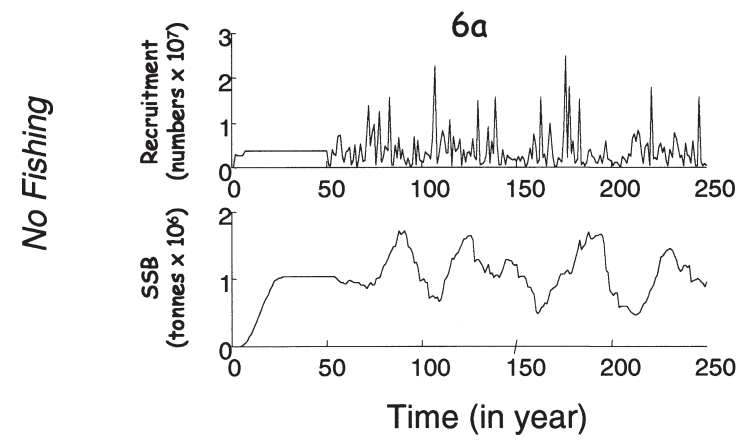

Fishing adults \& juveniles

$6 b$
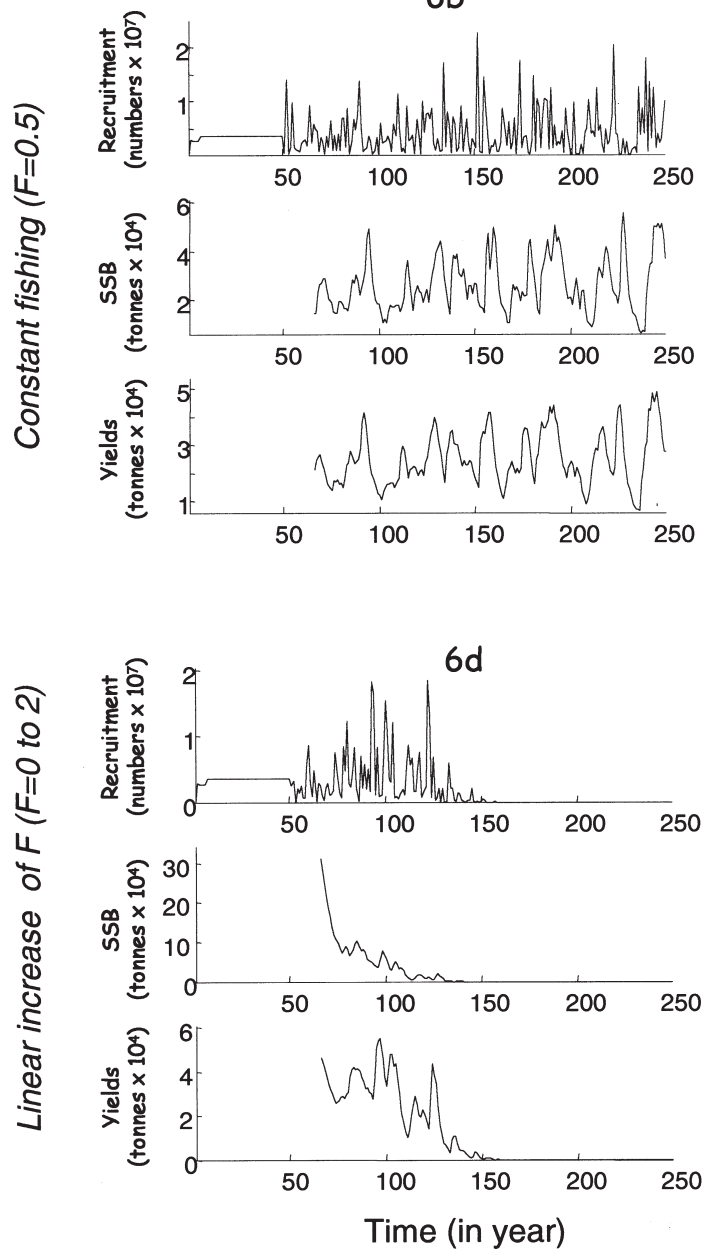

Fishing only adults

$6 c$
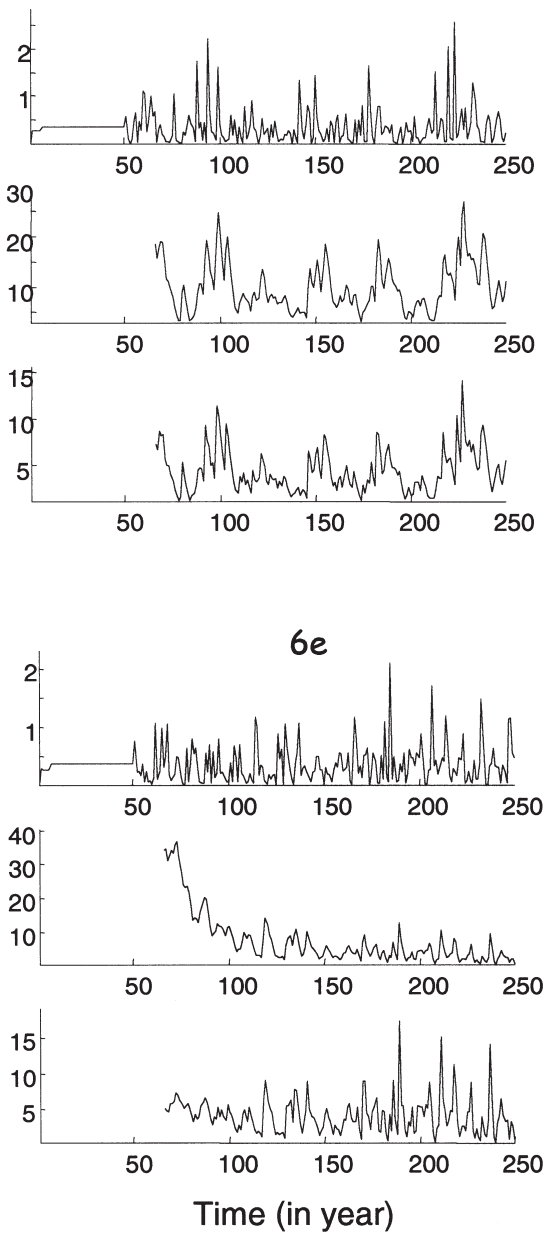

FIG. 6. - Outputs of the simulation modelling. The time series include a transition period of 50 years (to reach the steady state) with constant recruitment and a period of 200 years with stochastic recruitment (Gamma distributed); a: recruitment and spawning stocks biomass (SSB) time series without fishing mortality; b: recruitment, SSB and yields time series considering a constant fishing mortality of 0.5 on both juveniles and adults. $\mathbf{c}$ same as $6 \mathrm{~b}$ but with fishing restricted to the adults; $\mathbf{d}$ and e same as $6 \mathrm{~b}$ and $6 \mathrm{c}$ respectively, considering a linear increase of $\mathrm{F}$ (with $\mathrm{F}=0$ to 2 ).

Simulations were run over 200 years, after a transition period of 50 years in order to reach a steady state for which the spawning stock biomass (SSB) is equal to $\sim 1$ million tonnes (all the biological parameters remain the same during the simulation and $\mathrm{F}$ is always nil during the transition period). After this transition, the simulated population was submitted to two fishing scenarios: (i) a constant scenario with $\mathrm{F}$ equal to 0.5 over the 200 years and (ii) a linear increase of $\mathrm{F}$ over the 200 years (with $\mathrm{F}$ going from 0 to 2). We considered two age-specific selectivity patterns: (i) all the fish greater than or equal to 1 year are fished (which is close to the actual fishing pattern) with $\mathrm{F}_{\text {age } 1}=\mathrm{F}_{\text {age } 2}=\ldots . \mathrm{F}_{\text {last-age }}$, and (ii) only 
adults are fished (for more details on the simulation modelling, see Fromentin and Fonteneau, 2001).

\section{Results of the simulation modelling}

When the BFT population remained unfished, the SSB displayed long-term fluctuations (Fig. 6a) resulting from the stochastic variations in recruitment. Actually, this property comes from the large number of age-classes in the BFT SSB. The calculation of the SSB of a population including 15 ageclasses and a stochastic recruitment is like operating a moving sum over 15 delayed noise terms, which alters the high frequencies into low frequencies (for more details see Fromentin, 2002).

In the scenario in which both juveniles and adults are fished and $\mathrm{F}$ is equal to 0.5 over all the 200 years, the SSB fell from 1 million tonnes down to 30000 tonnes. As in the previous scenario, the BFT SSB and the yields display conspicuous pseudo-cycles (Fig. $6 b)$. The total yields were about the same level as the SSB ( 25 000 tonnes), with a periodicity of about 20 years of high catches ( $\sim 0000$ tonnes) and low catches ( $\sim 10000$ tonnes). If $\mathrm{F}$ remains constant but only adults are fished, the temporal patterns are similar (Fig. 6c). However, the SSB and yields are significantly higher: $\sim 100000$ tonnes for the SSB and 48 000 tonnes for the yields (the SSB and the yield are about 3 and 2 times higher than previously, so the ratio between the SSB and the yields is now about 2 to 1 ).

The scenario in which both juveniles and adults are fished and with an increasing F (from 0 to 2) over the 200 years leads to recruitment overfishing, then rapidly to the collapse of the BFT population (Fig. 6d). The conspicuous pseudo cycles in the yields partially blurred the rapid decline in the catches. Because of the numerous age-classes, the BFT population displayed an important 'inertia', so over-exploitation was detected in the yields with delay (at $\mathrm{t}=120$, the yields were still high whereas the SSB was already strongly depleted). Considering the same scenario when only adults were fished led to contrasting results (Fig. 6e). There is no recruitment overfishing or collapse of the BFT population. Although the SSB of BFT fell to a rather low level at the end of the simulation $(\sim 25000$ tonnes), it could still sustain very high fishing mortality $(\mathrm{F}=2)$. There was no crash in the BFT yields, which only decreased slightly from the beginning to the end of the simulation. Here also, variations in the yields were large, with an alternation of high $(>120$ 000 tonnes) and low catch ( 10 000 tonnes) periods.

\section{Discussion about the simulation modelling}

All together these simulations gave three interesting indications: (i) stochastic variations in recruitment induce conspicuous long-term fluctuations in the SSB and yields (note that long-term variations have been recently described from historical bluefin tuna trap data by Ravier and Fromentin, 2001, see also Fig. 2); (ii) these pseudo-cycles and the age structure of this population make it more difficult to detect overfishing and depletion; and (iii) there is a clear interaction between age-at-maturity and fishing selectivity. Considering an increasing $\mathrm{F}$ and in the frame of our study design, the risks of depletion and crash were almost nil if only adults were fished, but very high if both juveniles and adults were targeted. As BFT has 4.5 juvenile classes, an exploitation starting at age 1 indeed implies an important cumulative mortality throughout the juvenile stages, so the number of new spawners is relatively low ( $\mathrm{F}=0.5$ from age 1 implies that less than $10 \%$ of the recruitment can survive until the youngest adult stage). Furthermore, targeting only adults induced much higher yields because of the large difference in weight between BFT juveniles and adults (mean weight is $\sim 10 \mathrm{~kg}$ and $\sim 200 \mathrm{~kg}$ for a juvenile and adult of BFT respectively). As the scientific community suspects that the East Atlantic and Mediterranean BFT is overexploited (ICCAT, 1999), these simulations suggest that ICCAT should reinforce the current measures on the size limit and ask for the reinforcement of their controls. Note that size limit is particularly relevant for the BFT fishery which is mostly species- and size-specific (purse-seine fishermen even being able to evaluate the size of the fish before fishing it).

\section{CONCLUSION}

In the first part, we presented the main uncertainties related to the stock assessment and management of the Northeast Atlantic and Mediterranean bluefin tuna. Improving standard stock assessment procedure would firstly involve reducing these subjective uncertainties, and it therefore appears necessary to consider the perverse effects related to the implementation of a TAC on the East BFT stock. There is no doubt that this management measure has increased the level of mis- and under-reporting and decreased the quantity and quality of information related to the fishing effort. The official statistics 
have become less and less trustworthy and their deterioration will probably continue without the implementation of efficient controls of the present rules. Consequently, the standard stock assessment procedure based on official statistics is now inoperative.

Second part of this study tried to show how alternative methods could provide useful information to help the short-term management of this stock, which is needed since overfishing is strongly suspected. The results of simulation modelling showed that year-to-year variations in recruitment can induce conspicuous long-term fluctuations in the SSB and yields, which makes more difficult to detect overfishing and depletion. Simulations also confirmed that measures on the size limit are noticeably relevant for BFT. Simulation modelling can actually tackle various other management issues. Kell et al. (2000) used simulation modelling to test how longterm fluctuations in BFT stock size could bias biological reference points estimates, such as MSY. Modelling various sources of biological information can also be useful. The analysis of weight-at-age that we reported here, allows to test what the biologists have suspected for years, i.e. the year-to-year variations in weight-at-age and possibly in growth. This type of analysis could provide additional useful information about the population dynamics and, in some cases, about the state of the stock.

Other alternative methods could also help the management and one of them, i.e. the computation of a fishery-independent index of abundance based on aerial surveys, is currently investigated for the Northeast Atlantic and Mediterranean bluefin tuna (Fromentin, 2001). However, improvement of the scientific basis for fish stock assessment and prediction (the aim of the concerted action SAP) cannot be reached for the East Atlantic and Mediterranean BFT without a strong political determination, in order to report the real catch and effort data and to enforce the controls of the current management measures, i.e. TAC and size limit.

\section{ACKNOWLEDGEMENTS}

Thanks are due to Bernard Liorzou and JeanLouis Bigot, who provided sale records of the French seafood traders, Francois Doumenge, Henri Farrugio and Alain Fonteneau for the historical trap data and François Gauthiez and Frédéric Ménard for statistical advice. I also thank the anonymous referee for his helpful comments. The
European programme 'STROMBOLI' (DG XIV, contract 99/022) gave financial support to this study.

\section{REFERENCES}

Anonymous. - 1998. Preparatory meeting to ICCAT workshop on bluefin tuna \& SCRS meeting. CEFAS. Lowestoft. 29 June-3 July 1998.

Aristotle. $-4^{\text {th }}$ century BC. Les migrations des poissons. In: Histoire des animaux. Gallimard - folio essais, Paris.

Astthorsson, O.S. and A. Gislason. - 1998. Environmental conditions, zooplankton, and capelin in the waters north of Iceland. ICES J. Mar. Sci., 55: 808-810.

Beverton, R.J.H. and S.J. Holt. - 1957. On the dynamics of exploited fish populations. Fish. Investig. London Ser. 2, 19: 533 pp.

Block, B.A., H. Dewar, S.B. Blackwell, T.D. Williams, E.D. Prince, C.J. Farwell, A. Boustany, S.L.H. Teo, A. Seitz, A. Walli and D. Fudge. - 2001. Migratory movements, depth preferences, and thermal biology of Atlantic bluefin tuna. Science, 293: $1310-1314$.

Cushing, D.H. - 1982. Climate and fisheries. Academic Press, London.

Cushing, D.H. - 1995. Population production and regulation in the sea: a fisheries perspective. Cambridge University Press, Cambridge.

Desse, J. and N. Desse-Berset. - 1994. Stratégies de pêche au $8^{\text {ème }}$ millénaire : les poissons de Cap Andreas Kastros (Chypre). In: Le Brun A. (eds.); Fouilles récentes à Khirokitia. pp. 335-360. Editions Recherche sur Civilisations, Paris.

Doumenge, F. - 1998. L'histoire des pêches thonières. Col. Vol. Sci. Pap. ICCAT, 50(2): 753-803.

Engen, S. and R. Lande. - 1996. Population dynamic models generating species abundance distributions of the gamma type. $J$. Theor. Biol., 178: 325-331.

Fonteneau, A. and J.-M. Fromentin. -2000. An overview on the use of precautionary approach and tuna management. Col. Vol. Sci. Pap. ICCAT, 51: 2085-2094.

Fromentin, J.-M. - 2001. Interim Report of STROMBOLI - EU-DG XIV project 99/022. European Community - DG XIV. Brussels.

Fromentin, J.-M. - 2002. Can stochastic variations in recruitment induce long-term fluctuations in the carrying capacity? Col. Vol. Sci. Pap. ICCAT, 54: 985-991.

Fromentin, J.-M. and A. Fonteneau. - 2001. Fishing effects and life history traits: a case-study comparing tropical versus temperate tunas. Fish. Res., 53: 133-150.

Fromentin, J.-M., R.M. Myers, O. Bjørnstad, N.C. Stenseth, J. Gjøsæter and H. Christie. - 2001. Effects of density-dependent and stochastic processes on the stabilization of cod populations. Ecology, 82: 567-579.

Geromont, H.F. and D.S. Butterworth. - 1997. Specifications for the ADAPT VPA code, September 1996. Col. Vol. Sci. Pap. ICCAT, 46: 321-324.

Hjort, J. - 1914. Fluctuations in the great fisheries of northern Europe. Viewed in the light of biological research. Rapp. P.-v Réun. Cons. int. Explor. mer, 20: 1-228.

ICCAT. - 1997. 1996 SCRS detailed report on bluefin tuna. Col. Vol. Sci. Pap. ICCAT, 46: 1-301.

ICCAT. - 1999. 1998 SCRS detailed report on bluefin tuna. Col. Vol. Sci. Pap. ICCAT, 49: 1-191.

ICCAT. - 2002. ICCAT workshop on bluefin tuna mixing. Col. Vol. Sci. Pap. ICCAT (in press).

Kell, L., J.-M. Fromentin, F. Gauthiez and V. Restrepo. - 2000. A simulation framework to evaluate management strategies for Atlantic tunas: a preliminary example based on East Atlantic bluefin tuna. Col. Vol. Sci. Pap. ICCAT, 51: 2095-2116.

Labelle, M., T. Hoch, B. Liorzou and J.L. Bigot. - 1997. Indices of bluefin tuna (Thunnus thynnus thynnus) abundance derived from sale records of French purse seine catches in the Mediterranean Sea. Aquat. Liv. Res., 10: 329-342.

Liorzou, B. - 1999. Consolidate Interim Report of the EU project BFTMED 97/029. European Community - DG XIV. Brussels.

Lutcavage, M., R.W. Brill, G.B. Skomal, B.C. Chase and P.W. Howey. -1999 . Results of pop-up satellite tagging of spawning size class fish in the Gulf of Maine: do North Atlantic bluefin 
tuna spawn in the mid-Atlantic? Can. J. Fish. Aquat. Sci., 56: 173-177.

Mather, F.J., J.M. Mason Jr and A. Jones. - 1995. Historical document: life history and fisheries of Atlantic bluefin tuna. NOAA Technical Memorandum N.M.F.S., Miami.

May, R.C. - 1974. Larval mortality in marine fishes and the critical period concept. In: Blaxter J.H.S. (eds.), The early life history of fish. pp. 3-19. Springler-Verlag, New-York.

McCullagh, P. and J.A. Nelder. - 1989. Generalized Linear models. Chapman and Hall, London.

Myers, R.A. and N.G. Cadigan. - 1993. Is juvenile natural mortality in marine demersal fish variable? Can. J. Fish. Aquat. Sci., 50: $1591-1598$.

Nilssen, E.M., T. Pedersen, C.C.E. Hopkins, K. Thyholt and G. Pope. - 1994. Recruitment variability and growth of Northeast Arctic cod: influence of physical environment, demography, and predator-prey energetics. ICES Mar. Sci. Symp., 198: 449-470.

Pline, l'ancien. - 1st century AD. Histoire Naturelle. Livre IX. Les Belles Lettres, Paris.

Porch, C.E. - 1997. A user's manual for VPA-2BOX Version 2.0. National Marine Fisheries Service. Miami.

Porch, C.E. and S.C. Turner. - 1999. Virtual population analyses of Atlantic bluefin tuna with alternative models of transatlantic migration. Col. Vol. Sci. Pap. ICCAT, 49: 291-305.

Porch, C.E., S.C. Turner and G.P. Scott. - 2001. Updated catch-atage analyses of West Atlantic bluefin tuna. Col. Vol. Sci. Pap. ICCAT, 52: 1052-1066.

Pusineri, C., C. Ravier and J.-M. Fromentin. - 2002. Retrospective analysis of the bluefin tuna Nordic fisheries data. Col. Vol. Sci. Pap. ICCAT, 54: 517-526.

Ravier, C. and J.-M. Fromentin. - 2001. Long-term fluctuations in the Eastern Atlantic and Mediterranean bluefin tuna population. ICES J. Mar. Sci., 58: 1299-1317.

Shepherd, J.G. and D. Nicholson. - 1991. Multiplicative modelling of catch-at-age data and its application to catch forecasts. ICES J. Mar. Sci., 47: 284-294.

Sogard, S.M. - 1992. Variability in growth rates of juvenile fishes in different estuarine habitats. Mar. Ecol. Prog. Ser., 85: 35-53.

S-Plus. - 1999. S-plus 2000, guide to statistics, Vol. 1 and 2. MathSoft, Inc., Seattle.

Tiews, K. - 1963. An attempt to estimate the rate of transatlantic exchange of large bluefin tuna from German tuna catches by means of the feeding condition factor K. Int. Counc. Explor. Sea. Ann. Biol., 19: 183-184.

Tiews, K. -1978 . On the disapperance of bluefin tuna in the North Sea and its ecological implications for herring and mackerel. Rapp. P.-v. Réun. Cons. int. Explor. Mer, 172: 301-309.

Venables, W.N. and B.D. Ripley. - 1999. Modern applied statistics with S-Plus. Third edition. Springer, New-York.

Wooster, W.S. and K.M. Bailey. - 1989. Recruitment of marine fishes revisited. In: Beamish R.J. and G.A. McFarlane (eds). Effects of ocean variability on recruitment and an evaluation of parameters used in stock assessment models. Can. Spec. Pub. Fish. Aquat. Sci., 108: 153-159.

Wootton, R.J. - 1990. Ecology of Teleost fishes. Chapman \& Hall, London. 